\title{
Reflexões sobre perspectivas da pós-graduação
}

\author{
Alcino Lázaro da Silva* \\ *Professor Titular de Cirurgia do Aparelho Digestivo da Universidade Federal de Minas Gerais (UFMG).
}

\section{Pós-graduação estrito-senso}

A Pós-Graduação (PG) divide-se em lato-senso (Residência) e estrito-senso (Docência - Pesquisa). Esta, em Mestrado e Doutorado. O Mestre não adquire autonomia. Depende, ainda, de seu Orientador. O Doutor, completado o curso, passa a gerar idéias independentemente do Orientador. O excepcional ou o gênio não se enquadram nessa graduação. Criada na década de 60, antecipando-se à extinção da cátedra e ao desastroso aparecimento do sistema departamental, nela se integraram os experientes, os sábios, os vividos, os destaques e os sonhadores. Em seguida à extinção da cátedra, em 1968, instalou-se na universidade brasileira uma sedenta avalancha de reforma curricular. Nesta, os experientes se recolheram não acreditando no acontecimento; os jovens assumiram o mando político; as reformas se instalaram e os experientes foram colocados à margem. Por exemplo, deixando chefias de serviços de escol para serem designados em disciplinas ambulatoriais. A saída foi fortificar a pós-graduação estrito-senso; sair da ação avassaladora que destruiu a hierarquia de competência e continuar a formar jovens, agora, sob outra política (ação), a da liderança natural e competente. Acredito que essa atitude dos nomes competentes e de destaque foi a tábua de salvação da universidade. Enquanto os jovens, os políticos e os ambiciosos a cargos de comando (mesmo sem competência) assumiam as lideranças, até trocando de lugares para se sustentarem nos cargos ou funções, os líderes se organizaram em cursos e nestes mantiveram a chama maior da universidade - a de formar valores humanos! Os anos se passaram, os sem preparo se perderam, outros desistiram, outros se aposentaram precocemente, outros foram cuidar de seus interesses particulares e se confirmou o dito de que o idealismo é superior e mais duradouro que a ideologia. A Lei de Diretrizes e Bases da Educação Nacional, nº 4.024/61, art. 69, letras b e c pela primeira vez refere-se à Pós-Graduação com dois cursos:

- de Pós-graduação, após a graduação

- de Especialização, Aperfeiçoamento e Extensão

O parecer do CFE, relatado por Newton Sucupira, $n^{\circ}$ 977/65, dá forma à PG estrito-senso objetivando:

- Pós-graduação estrito-senso

- Pós-graduação lato-senso

A Lei no 5.540 de 28/11/68 estabelece:

- Graduação

- Pós-graduação

- Especialização e Aperfeiçoamento

- Extensão
No parecer de $n^{0} 77 / 69$, fixam-se as normas para o credenciamento dos CPG. O parecer 576/70, relatado por Monis Aragão, estabelece normas complementares para a PG na área médica, aceitando a Residência como instrumento de PG e introduzindo as disciplinas de Didática Especial e Pedagogia Médica e a participação obrigatória do aluno em trabalhos de pesquisas.

\section{Residência médica e pós-graduação}

- Legislação e Regulamentação -

1889 Halsted na John Hopkins cria a Residência

1900 W. Osler o faz na Clínica

1917 A Associação Médica Americana criou o "Council on Medical Education and Hospitals

1927 Surgiu a $1^{a}$ lista de hospitais credenciados por este 1945 Início na USP

1947 Hospital dos Serv. Do Estado do Rio de Janeiro

1958 Oftalmologia e Cirurgia Geral, UFMG

1962 Viña Del Mar (Chile), $3^{\mathrm{a}}$ reunião de Faculdades de Medicina Latino-Americanas

1964 Poços de Caldas (MG), idem (4 $\left.4^{\mathrm{a}}\right)$, recomendam a Residência como sistema apropriado à formação de especialista

1965 Parecer CFE 977 cria a pós-graduação stricto-sensu e lato-senso

1968 Dec. N 63.343 de 1-10 cria os Centros Regionais de PG

1969 Parecer CFE 77 fixa critérios de credenciamento

1969 Dec-Lei 465 em 11.02.69 equipara vencimentos de assistentes, que obtiver grau de doutor, ao de adjunto e título de doutor para este

1970 Parecer CFE 576, identifica a Residência como sistema pedagógico ideal.

1977 Em 05.09.77 institucionalizou-se a residência como modalidade de ensino pós-graduado (Dec. 80.281)

1977 Resolução 11, CFE, estabelece normas para credenciamento

1977 Resolução 14 CFE dispõe sobre cursos de Aperfeiçoamento e Especialização

1978 A CNRM passou a elaborar normas na Resolução 04

1979 Resolução 05 da CNRM estabelece normas para programas de Residência

1980 Dec. Lei 85.587 permite a progressão no magistério sem cursos de pós-graduação

1981 Em 07.07.81 regulamentação trabalhista da Residência

1981 Em 06.05.81 a CAPES recomenda admissão ao magistério tanto para os portadores de Residência quanto de pós-graduação

1981 Em 07.07.81, Lei 6.932 dispõe sobre as atividades do Residente

1981 Resolução 01 da CNRM estabelece especialidades médicas 
1981 Resolução 17 dispõe sobre duração das especialidades

1982 Resolução 09 cria a consultoria técnica da CNRM

1982 Resolução 11 dispõe sobre credenciamento de programas

1982 Parecer 505, CFE, dispõe sobre a integração docenteassistencial

1982 Resolução 1082 CFE estabelece concessão de título de especialista

1983 Resolução 05 fixa normas, funcionamento e credenciamento de pós-graduação

Como se observa, legislou-se e regulamentou-se muito sobre um assunto que me parece mais essência do que número. Para se fazer pós-graduação (implicada a Residência como início fundamental), em nível clínico, não basta legislar. É preciso operacionalizar. É preciso agir. Por esta razão, intrinsecamente, parece-me, pós-graduação não é número e nem legislação excessiva e sim estado de espírito. Senão, vejamos. Os princípios, na verdade, pretendem formar recursos humanos para a docência e a pesquisa, ou seja, produzir homens. $\mathrm{O}$ assunto foi amplamente discutido e divulgado na universidade brasileira e a Residência e o exercício da Pedagogia e da Didática se tornaram prioridades. A reforma universitária criou o departamento que foi muito mal copiado do exterior e anarquizou a hierarquia de competência, porque deixou de prestigiar a qualificação e a hierarquia, e passou a ser um ajuntamento de profissionais, sob o ponto de vista administrativo e político. Em 1988, na Rev. Col. Bras. Cir., propusemos uma contra-reforma visando à competência e aos valores positivos sobretudo àqueles que retratam professores que investem na qualificação e na produção de homens. Essa necessidade se consubstancia, pois o MEC no seu Documento II, de 02/08/2004, reafirma princípios e consolida diretrizes de Reforma da Educação Superior. Eis aí a questão: reformar a reforma porque esta não satisfez à grandeza de uma universidade. No âmago desse contexto está a PG, com uma diferença. Ela não se alterou, ela se consolida, ela se aprimora e ela não deixou escapar a hierarquia de competência. Em conseqüência, os bons, os preparados, os idealistas, os qualificados, os sonhadores e os líderes não se abalaram com o transcurso da má-reforma e permaneceram no seu posto a formar homens e desdobrarse no crescimento intelectual da universidade. De sorte que frente ao inesperado da implantação do Documento II os que acreditam na hierarquia de competência continuarão no mesmo mister e só poderão acrescentar qualidade ao que vier, de bom ou de discutível. Assim pensando, as perspectivas da PG continuarão a ser as mesmas. Idealismo, qualidade, luta por crescimento, desdobramentos e formação de homens. Nada será alterado ou retirado, a exemplo do que ocorreu outrora. Ao contrário, todos os que militaram ou exercem a PG têm muito subsídio a oferecer aos que estudarão e determinarão as reformas necessárias a uma universidade grande, técnica, moral, ética, avançada e criativa.

\section{Em resumo:}

A Capes, ao invés de exigir publicação no exterior em revista de impacto, deveria (e há dinheiro para isto) criar a sua própria e brasileira, para que se inicie o processo de motivar os alienígenas a lerem o que há de bom no Brasil. Pós-Graduação é estado de alma (espírito). Gosta-se ou não dessa atividade e ela só é eficaz nos locais onde a Instituição não é o sujeito e sim a aglutinadora. A liderança e a criatividade são de um só ou de um grupo de homens docentes-pesquisadores.

\section{Universidade e competência}

Outra reflexão que precisa ser considerada é sobre a universidade. Ela, teórica e filosoficamente, é universal. Ela aglutina os elementos da elite intelectual e os potencialmente qualificados a atingirem esse patamar para juntos com os administradores, fazerem do país uma nação do saber, da criatividade, da reflexão e do crescimento, como povo que se resguarda, pontifica-se e faz crescer os que ambicionam esse desiderato. O Brasil, apesar de grandes feitos e realizações, por parte do seu povo, em termos universitários, a nosso ver, é uma nação emergente. A sua universalidade, ainda é imatura e pueril em relação às civilizações que existem ou existiram como marcos do desenvolvimento dos seres humanos e de um povo que se respeita e se faz respeitar. Nós nos julgamos um membro da universidade, um ser apaixonado e um trabalhador em favor de sua causa, ou seja, o desenvolvimento técnico e criativo. Somos uma peça no que toca ao trabalho quotidiano. Não nos colocamos entre os mais criativos, os que transformam conceitos, os que criam idéias e, obviamente, os gênios. Colocamo-nos entre os trabalhadores. Por trabalhar e por sonhar desde que passamos pela porta principal de entrada, não desistimos da idéia de progresso pessoal e de fazer outros progredirem. Já se vão 45 anos de exercício pleno. Vivido esse período cabe-nos uma reflexão retrospectiva. Buscamos o universal que deve ser hierarquizado na competência. Não na transação, no embate, no apadrinhamento, no fisiologismo, no nepotismo, na habilidade política, na malversação e no descumprimento do dever. Vivemos inteiramente, em busca do aprimoramento e da provocação aos mais jovens. Hoje, refletindo, ainda temos nossas dúvidas sobre a realidade desse sonho. Ela ainda não é universal e não é hierárquica, no sentido da competência. Deixamos uma organização de mando absoluto, bom ou mal, produtivo ou não e passamos, rapidamente, para um sistema horizontal, pseudodemocrático, em que os valores se nivelaram por baixo. Antes, o comando era absoluto e pessoal, agora é colegiado e diluído na competência e na competição. Por quê, então, a despeito desse hiato hierárquico, a universidade brasileira cresce e colabora com o país no seu desenvolvimento. Por causa, não tenho dúvidas, do individualismo qualificado. Na falta de equipes uníssonas e hierarquizadas, no saber e na experiência, sobreviveu o crescimento à custa de numerosos bons que não se abalaram e persistiram na idéia de crescer e fazer crescer. Sem julgar que estou com insanidade mental, após 45 anos, a universidade brasileira se desenvolve porque existem bons que trabalham e se doam em favor dos que ambicionam a excelência. Ela é universal porque os indivíduos são grandes, apesar de conviverem em pequenos ou restritos grupos. De agora em diante, há necessidade de buscar a retomada da hierarquia, mas que não seja absoluta e nem draconiana. 
Há necessidade de reformar a reforma e criar a verdadeira hierarquia de competência, na geração de idéias, na prestação de serviço, na administração e no respeito à rigorosa aplicação de recursos, tanto externos como da própria universidade. Concluindo, estamos no estágio individual que pontifica a universidade, mas se a reforma não vier e restabelecer a hierarquia de competência plena, jamais poderemos competir em nível internacional com eficiência e eficácia.

Correspondência:

Prof. Alcino Lázaro da Silva

R. Guaratinga, 151

30315-430 Belo Horizonte - MG

\section{ACTA CIRÚRGICA BRASILEIRA NO MEDLINE}

\section{Prof. Saul Goldenberg \\ Fundador e Editor Chefe}

Após a análise do LITERATURE SELECTION TECHNICAL REVIEW COMMITTEE, integrada por autoridades de reconhecido saber no campo da biomedicina, tais como: médicos, pesquisadores, educadores, editores, bibliotecários em ciências da saúde e historiadores, recomendaram a inclusão da Acta Cirúrgica Brasileira no NATIONAL LIBRARY OF MEDICINE'S , MEDLARS SYSTEM.

Foi enviada carta nos seguintes termos:

"I am pleased to inform you that ACTA CIRÚRGICA BRASILEIRA has been selected to be indexed and included in MEDLINE."

"Databases in the MEDLARS system are available online in the U.S. and throughout the world."

Este foi o presente especial que a Acta Cirúrgica Brasileira recebeu após completar 18 anos.

MEDLINE is the National Library of Medicine's premier bibliographic database covering the fields of medicine, nursing, dentistry, veterinary medicine, the health care system, and the preclinical sciences. 